\title{
Fabrication of Ag-modified hollow titania spheres via controlled silver diffusion in $\mathrm{Ag}-\mathrm{TiO}_{2}$ core-shell nanostructures
}

\author{
Bartosz Bartosewicz, Malwina Liszewska, Bogusław Budner, \\ Marta Michalska-Domańska, Krzysztof Kopczyński and Bartłomiej J. Jankiewicz*
} Open Access

\author{
Letter \\ Address: \\ Institute of Optoelectronics, Military University of Technology, gen. S. \\ Kaliskiego 2, Warsaw 00-908, Poland \\ Email: \\ Bartłomiej J. Jankiewicz - bartlomiej.jankiewicz@wat.edu.pl \\ * Corresponding author \\ Keywords: \\ core-shell nanostructures; hollow spheres; silver diffusion; \\ silver-modified titanium dioxide; titania
}

\author{
Beilstein J. Nanotechnol. 2020, 11, 141-146. \\ doi:10.3762/bjnano.11.12 \\ Received: 26 July 2019 \\ Accepted: 06 January 2020 \\ Published: 10 January 2020 \\ Associate Editor: S. Giordani \\ (c) 2020 Bartosewicz et al.; licensee Beilstein-Institut. \\ License and terms: see end of document.
}

\begin{abstract}
Inorganic hollow spheres find a growing number of applications in many fields, including catalysis and solar cells. Hence, a simple fabrication method with a low number of simple steps is desired, which would allow for good control over the structural features and physicochemical properties of titania hollow spheres modified with noble metal nanoparticles. A simple method employing sol-gel coating of nanoparticles with titania followed by controlled silver diffusion was developed and applied for the synthesis of Ag-modified hollow $\mathrm{TiO}_{2}$ spheres. The morphology of the synthesized structures and their chemical composition was investigated using SEM and X-ray photoelectron spectroscopy, respectively. The optical properties of the synthesized structures were characterized using UV-vis spectroscopy. $\mathrm{Ag}-\mathrm{TiO}_{2}$ hollow nanostructures with different optical properties were prepared simply by a change of the annealing time in the last fabrication step. The synthesized nanostructures exhibit a broadband optical absorption in the UV-vis range.
\end{abstract}

\section{Findings}

In recent years, nanometer- to micrometer-sized inorganic hollow spheres (HSs) have received increasing attention due to their potential application in a variety of areas [1-4] such as solar energy conversion or photocatalysis [2,5-7]. Among them, of great interest are $\mathrm{TiO}_{2}$ HSs modified with plasmonic nanoparticles (NPs), which allow for the combination of the photocatalytic properties of $\mathrm{TiO}_{2}$ and the optical properties of plas- monic NPs [2]. This combination has been shown to extent the photocatalytic activity of $\mathrm{TiO}_{2}$, which is initially limited to UV light [8], to the visible or even to the NIR range of radiation [9].

Recent examples of the fabrication of plasmonic NP-modified $\mathrm{TiO}_{2}$ HSs are based mainly on multistep processes including hard-templating methods [10-19]. Au-modified $\mathrm{TiO}_{2} \mathrm{HSs}$ of 
regular shape were prepared using a multistep process in which sulfonated polystyrene spheres were used as a hard-template [10]. The obtained composite catalyst exhibits a synergistic effect between the anatase crystalline shell and the AuNPs as well as superb thermal and mechanical stability of the highly dispersed AuNPs. $\mathrm{TiO}_{2}$ HSs decorated with ultrasmall Ag nanocrystallites and exhibiting excellent photocatalytic properties were fabricated in a multistep process including a two-step hydrothermal treatment [11]. Ag-modified $\mathrm{TiO}_{2} \mathrm{HSs}$ showing efficient photocatalysis in the visible-light range were synthesized in a multistep process through a sacrificial core technique using $\mathrm{AgBr}$ as the core [12]. A hard-templating method with a silica template was used in the fabrication of rattle-type HSs of $\mathrm{Au} @ \mathrm{TiO}_{2}$ using multistep template deposition and a surfaceprotected etching method [13], of $\mathrm{TiO}_{2} \mathrm{HSs}$ of mixed anatase/ rutile composition loaded with noble metal NPs ( $\mathrm{Au}, \mathrm{Pt}, \mathrm{Pd}$ ) [14], and of N-doped $\mathrm{Ag} / \mathrm{TiO}_{2} \mathrm{HSs}$ [15]. A hard-templating method with a carbon template was used in a one-pot synthesis of uniform $\mathrm{TiO}_{2}-\mathrm{Ag}$ hybrid HSs [16], and of $\mathrm{Ag} / \mathrm{AgCl}$ modified self-doped $\mathrm{TiO}_{2} \mathrm{HSs}$ [17]. Finally, polymer spheres were used as hard-templates in a multistep fabrication of tri-modified $\mathrm{TiO}_{2} \mathrm{HSs}\left(\mathrm{Ag}-\mathrm{C} / \mathrm{N}-\mathrm{TiO}_{2}\right)$ [18], and of silver/TiO $2 \mathrm{HSs}$ [19].

Many papers dedicated to fabrication and application of plasmonic NP-modified $\mathrm{TiO}_{2}$ HSs have been published, including those mentioned above. In most cases the methodologies used are either complex or allow only for a limited control of the nanostructure morphologies and the resulting properties. In addition, we are not aware of any articles reporting the possibility to control the optical properties of plasmonic NP-modified $\mathrm{TiO}_{2}$ HSs by means of changes in their morphologies. In this work, we present the results of studies on the fabrication of Ag-modified $\mathrm{TiO}_{2}$ HSs with broadband optical absorption through controlled silver diffusion in $\mathrm{Ag}-\mathrm{TiO}_{2}$ core-shell nanostructures (CSNs). Our approach comprises three simple steps starting from the synthesis of the metallic core, through its coating with titania and finally annealing leading to plasmonic hollow nanostructures with plasmon resonance in a broad spectral range. SEM microscopy was used to visualize changes occurring in the morphology of the nanostructures. XPS spectroscopy was used to provide information regarding the chemical composition of Ag-modified $\mathrm{TiO}_{2} \mathrm{HSs}$.

Figure 1 shows a schematic illustration of the formation of Ag-modified $\mathrm{TiO}_{2}$ HSs from $\mathrm{Ag} @ \mathrm{TiO}_{2}$ CSNs together with SEM images of the structures at different stages of their fabrication. We have demonstrated recently that AgNPs can be covered in a controlled manner with a smooth titania shell of variable thickness by the hydrolysis of organic titania precursors to form $\mathrm{Ag} @ \mathrm{TiO}_{2} \mathrm{CSNs}$ [20]. Examples of such structures are shown in Figure 1 (down left) and in Figure 2A. Interestingly, further thermal modification of these fabricated $\mathrm{Ag} @ \mathrm{TiO}_{2} \mathrm{CSNs}$ yields unexpected results. Annealing of $\mathrm{Ag} @ \mathrm{TiO}_{2}$ nanostructures in a muffle furnace results in $\mathrm{Ag}$ diffusion from the silver core into the titania shell. As a result, the gradual diminishment of the silver core $($ DP50 $=113 \mathrm{~nm})$ and the formation of much smaller Ag particles (diameter below $10 \mathrm{~nm}$ ) on the titania shell surface are observed. The metal diffusion into the titania shell has not been observed in the case of $\mathrm{Au} @ \mathrm{TiO}_{2} \mathrm{CSNs}$ fabricated using the same method as $\mathrm{Ag} @ \mathrm{TiO}_{2} \mathrm{CSNs}$. This is likely due to much lower reactivity of $\mathrm{Au}$ compared to $\mathrm{Ag}$. $\mathrm{Ag}-\mathrm{TiO}_{2}$ nanostructures at an intermediate and the final stage of thermal modification are shown in SEM images in Figure 1 and Figure 2B-E.

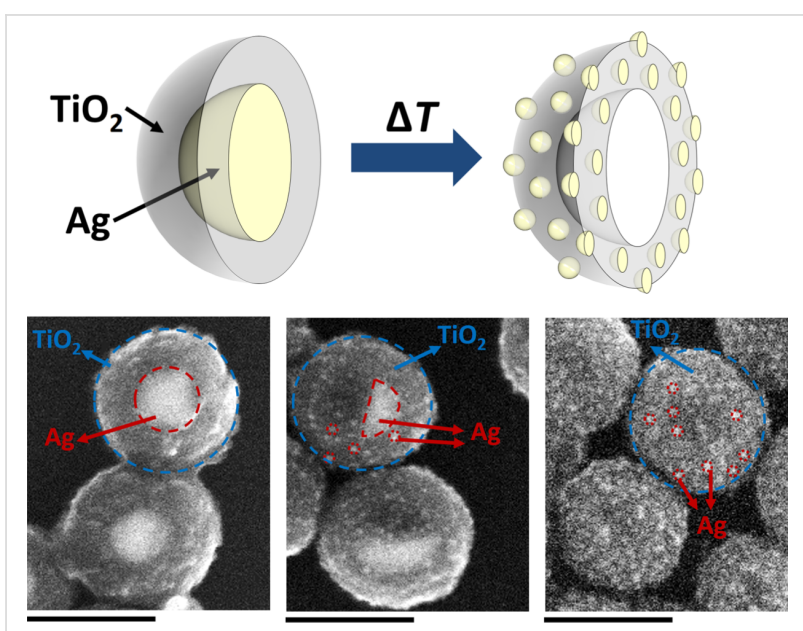

Figure 1: Formation of Ag-modified $\mathrm{TiO}_{2} \mathrm{HSs}$ (top) and SEM images showing $\mathrm{Ag}-\mathrm{TiO}_{2}$ nanostructures at different stages of their fabrication (bottom, scale bar $=200 \mathrm{~nm}$ ).

The SEM images in Figure 1 clearly indicate the titania shell, the Ag core and products of its thermal transformation, i.e., disappearing Ag cores and newly formed Ag nanoparticles. In the first image (Figure 1, bottom left) the Ag core is clearly visible as a bright circle. Upon thermal transformation, the $\mathrm{Ag}$ core becomes smaller and, depending on the initial CSNs and the annealing time, it will take on different shapes (Figure 1, bottom centre). It must be stated here that transformation does not occur identically in all CSNs in the given samples, as can be seen in Figure 2, and resulting optical properties will be a sum of the properties of all particles in the sample. If CSNs are annealed for a sufficiently long time the $\mathrm{Ag}-\mathrm{TiO}_{2}$ nanostructures shown in Figure 1 (bottom right) and Figure 2E are formed. These nanostructures are empty inside as indicated by a darker region of low average atomic number in the middle of the particles. They also have a high number of small AgNPs (much smaller than the size of the initial Ag core, below $10 \mathrm{~nm}$ ) present on the surface of the titania shell. 

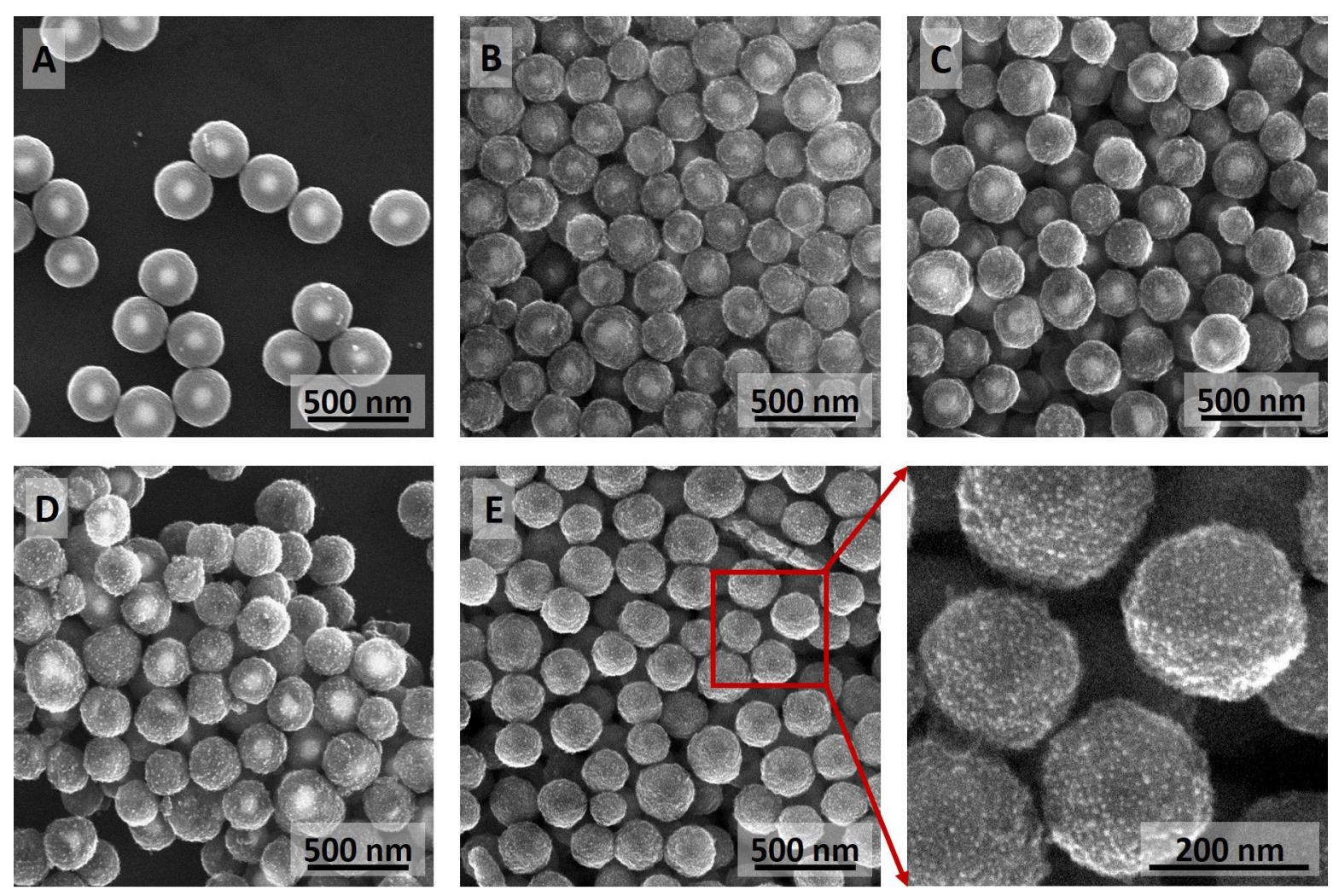

Figure 2: $\mathrm{SEM}$ images of freshly prepared $\mathrm{Ag}-\mathrm{TiO}_{2}$ core-shell nanostructures $(\mathrm{A})$ and $\mathrm{Ag}-\mathrm{TiO}_{2}$ core-shell nanostructures after annealing at $150{ }^{\circ} \mathrm{C}$ for $0.5 \mathrm{~h}(\mathrm{~B}), 1.5 \mathrm{~h}(\mathrm{C}), 3 \mathrm{~h}(\mathrm{D})$, and $12 \mathrm{~h}(\mathrm{E})$.

The process of formation of Ag-modified $\mathrm{TiO}_{2} \mathrm{HSs}$ can be controlled simply by the annealing time, and as a result, nanostructures of different morphologies can be obtained (Figure 2). At shorter annealing times (Figure 2B-D) the diffusion in $\mathrm{Ag}-\mathrm{TiO}_{2} \mathrm{CSN}$ does not occur at the same speed. This is indicated by the presence of $\mathrm{Ag}-\mathrm{TiO}_{2}$ nanostructures with cores at different stages of size reduction, including nanostructures with intact cores (Figure 2B-D). However, after longer annealing times in all $\mathrm{Ag}-\mathrm{TiO}_{2} \mathrm{CSNs}$, silver cores were fully converted to Ag species (i.e., positively charged Ag clusters as discussed below or other subnanometric silver species) embedded in a titania shell or smaller AgNPs located at the shell surface (Figure $2 \mathrm{E}$ ).

To the best of our knowledge, the silver diffusion in $\mathrm{TiO}_{2}$ nanostructures has been only investigated in the case of $\mathrm{TiO}_{2}$ thin films [8,21-24] and our studies are probably the first to discuss this process occurring in $\mathrm{Ag} @ \mathrm{TiO}_{2} \mathrm{CSNs}$. Based on our results and the diffusion mechanism proposed for AgNPs on titania films [8,21], the silver diffusion in $\mathrm{Ag} @ \mathrm{TiO}_{2} \mathrm{CSNs}$ can occur in the following manner. Titania is oxidized in an air atmosphere and as a result, holes, which may further oxidize AgNPs surrounded by the titania shell, are generated. Upon oxidation, AgNPs gain a positive electric charge and may eject positively charged $\mathrm{Ag}$ clusters. In case of $\mathrm{Ag} @ \mathrm{TiO}_{2} \mathrm{CSN}$ and depending on the annealing time, these ejected Ag clusters may either be accommodated within or on the titania shell. In the titania shell, these silver clusters could react with the $\mathrm{TiO}_{2}$ host through the formation of a complex $\left[\mathrm{Ag}-\left(\mathrm{TiO}_{2}\right)\right]$ [21]. Upon reaching the surface of the titania shell positively charged silver species could also form AgNPs much smaller than the core of the initial $\mathrm{Ag} @ \mathrm{TiO}_{2}$ CSNs. These small AgNPs are responsible for the observed optical properties of Ag-modified $\mathrm{TiO}_{2} \mathrm{HSs}$. The proposed mechanism of silver diffusion and especially the importance of oxygen molecules are supported by the fact that when freshly prepared $\mathrm{Ag} @ \mathrm{TiO}_{2} \mathrm{CSN}$ s are placed in the XPS spectrometer and annealed under vacuum, without the presence of oxygen, no silver diffusion is observed.

The analysis of the $\mathrm{Ag} 3 \mathrm{~d}$ band shows that silver is present in Ag-modified $\mathrm{TiO}_{2} \mathrm{HSs}$ in at least three different forms, i.e., $\mathrm{Ag}$ metal, oxides $\left(\mathrm{AgO} / \mathrm{Ag}_{2} \mathrm{O}\right)$ and probably in the form of alloys (Figure 3). This observation suggests that silver is present in fabricated nanostructures not only in the form of AgNPs on the surface of the hollow $\mathrm{TiO}_{2}$ spheres, but is also embedded in the other forms within the $\mathrm{TiO}_{2}$ HSs. The position and shape of the peaks of metallic silver were determined based on measurements of a silver plate with a purity of $99.97 \%$. The half-width 


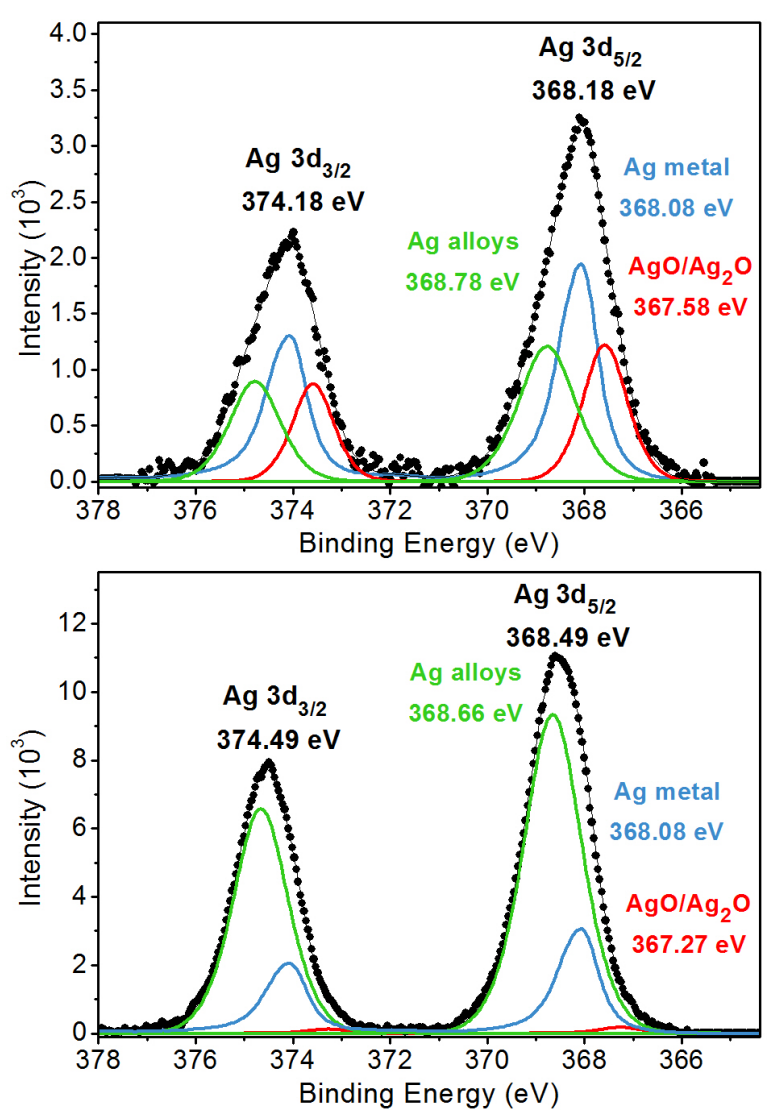

Figure 3: XPS Ag $3 d_{1 / 2}$ and $A g ~ 3 d_{5 / 2}$ spectra of freshly prepared $\mathrm{Ag}-\mathrm{TiO}_{2}$ core-shell structures (top) and after annealing at $150{ }^{\circ} \mathrm{C}$ for $12 \mathrm{~h}$ (bottom).

of the $\mathrm{Ag} 3 \mathrm{~d}_{5 / 2}$ peak of metallic $\mathrm{Ag}$ is approximately $0.95 \mathrm{eV}$ and its maximum lies at $386.08 \mathrm{eV}$, which is consistent with the data in the literature [25]. The peak associated with silver oxide appears at lower binding energies than the peak of metallic silver [26,27]. Due to the very small offset for different forms of silver oxide, only one peak located between 367.27 and $367.58 \mathrm{eV}$ with a half-width of $1.03-1.07 \mathrm{eV}$ was modeled in the spectra. The third peak with a maximum between 358.66 and $358.78 \mathrm{eV}$ and a half width of $1.36-1.40 \mathrm{eV}$ was assigned to a silver alloy with titanium. Its location cannot be linked to any oxidation state of silver. Such a shift of the $\mathrm{Ag} 3 \mathrm{~d}_{5 / 2}$ peak can only come from alloys of silver with metals of lower electronegativity [28]. Wang and collaborators obtained this effect for an $\mathrm{Ag} / \mathrm{Al}$ alloy in which $\mathrm{Ag}$ and $\mathrm{Al}$ have electronegativity values of 1.93 and 1.61, respectively [28]. We believe that a similar situation occurs in the case of $\mathrm{Ag}-\mathrm{TiO}_{2}$ nanostructures due to the electronegativity of $\mathrm{Ti}$ (1.54) being lower than the electronegativity of Ag.

The UV-vis spectra of aqueous suspensions of freshly prepared $\mathrm{Ag} @ \mathrm{TiO}_{2} \mathrm{CSNs}$ (Figure 4A) and nanostructures resulting from

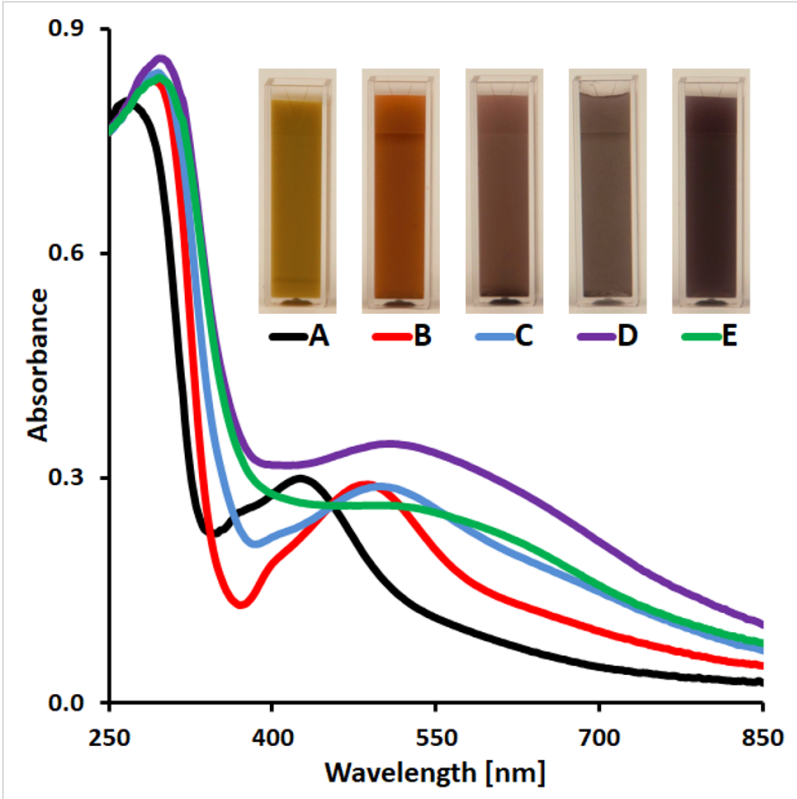

Figure 4: UV-vis spectra and images of aqueous suspensions of freshly prepared $\mathrm{Ag}-\mathrm{TiO}_{2}$ core-shell nanostructures $(\mathrm{A})$ and after annealing in $150^{\circ} \mathrm{C}$ for $0.5 \mathrm{~h}(\mathrm{~B}), 1.5 \mathrm{~h}(\mathrm{C}), 3 \mathrm{~h}(\mathrm{D})$ and $12 \mathrm{~h}(\mathrm{E})$.

their annealing at $150{ }^{\circ} \mathrm{C}$ for $0.5 \mathrm{~h}$ (Figure 4B), $1.5 \mathrm{~h}$ (Figure 4C), $3 \mathrm{~h}$ (Figure 4D) and $12 \mathrm{~h}$ (Figure 4E) are shown in Figure 4. To better visualize the optical properties of the fabricated $\mathrm{CSNs}$ and Ag-modified hollow $\mathrm{TiO}_{2}$ nanostructures, images of their aqueous suspensions are also shown in the inset of Figure 4. As we have shown previously, coating of AgNPs with $\mathrm{TiO}_{2}$ leads to an overall increase in the refractive index of their local dielectric environment and, as a result, to a red-shift of the plasmon resonance [20]. As can be seen from curve A in Figure 4, Ag@ $\mathrm{TiO}_{2}$ CSNs have a broad absorption in the UV-vis range. This is the characteristic absorption of these composites, which does not change remarkably with a change of the shell thickness. The annealing of Ag@ $\mathrm{TiO}_{2} \mathrm{CSNs}$ leads to nanostructures with significantly changed optical properties as can be seen from curves B-E in Figure 4. In all cases, a redshift of the maximum of absorption and a strengthening and widening of the plasmon resonance bands were observed. It is significant that the Ag-modified $\mathrm{TiO}_{2}$ hollow nanostructures show a broad and relatively strong absorption in the whole investigated spectral range, which corresponds to over $60 \%$ of the energy in the solar energy distribution [29].

The changes observed in the optical properties of the Ag-modified $\mathrm{TiO}_{2} \mathrm{HSs}$ compared to $\mathrm{Ag} @ \mathrm{TiO}_{2} \mathrm{CSN}$ are related to several changes occurring in the nanostructure morphology. Any interactions affecting the optical properties of these CSNs occurred only between a single silver core and the titania shell. Based on the proposed mechanism, the annealing gradually led to a transformation of the single and relatively large core 
$($ DP50 $=113 \mathrm{~nm})$ into multiple and tiny silver clusters, which with increasing annealing time were moving through the titania shell toward its edge and were finally forming AgNPs of different size. Therefore, the resulting optical properties represent the sum of the change of number, size and shape of the AgNPs, their local environment (in the final structure many small AgNPs are located on the interface between $\mathrm{TiO}_{2}$ and water), and the plasmon-plasmon coupling between the AgNPs on the titania shell [21].

In summary, we have shown herein a simple and template-free approach to the fabrication of Ag-modified hollow $\mathrm{TiO}_{2}$ spheres via controlled silver diffusion in $\mathrm{Ag}-\mathrm{TiO}_{2} \mathrm{CSNs}$. $\mathrm{Ag}-\mathrm{TiO}_{2} \mathrm{CSNs}$ of different shell thicknesses, which are fabricated via a previously developed method, can be further modified by annealing to form $\mathrm{Ag}$-modified hollow $\mathrm{TiO}_{2}$ spheres with different morphologies. Hollow nanostructures with a variable amount of AgNPs on the shell surface and with different optical properties resulting from the structural differences can be fabricated simply by control of the annealing time. Fabricated $\mathrm{Ag}-\mathrm{TiO}_{2}$ hollow nanostructures exhibit a broader and larger optical absorption in the $\mathrm{UV}$-vis range than the $\mathrm{Ag}-\mathrm{TiO}_{2}$ CSNs they are made from. In addition, a significant number of AgNPs can be observed on their surface and, therefore, based on the existing literature, these nanostructures should be of great interest for applications in solar light-driven photocatalysis and photovoltaics [30].

\section{Supporting Information}

\section{Supporting Information File 1 \\ Materials and methods. \\ [https://www.beilstein-journals.org/bjnano/content/ supplementary/2190-4286-11-12-S1.pdf]}

\section{Funding}

This work was financially supported by the Polish National Science Centre [Grant no. 2011/03/D/ST5/06038].

\section{ORCID ${ }^{\circledR}$ iDs}

Bartosz Bartosewicz - https://orcid.org/0000-0002-8053-6563 Malwina Liszewska - https://orcid.org/0000-0001-5102-641X Bogusław Budner - https://orcid.org/0000-0002-9395-6073 Marta Michalska-Domańska - https://orcid.org/0000-0002-8684-3230 Krzysztof Kopczyński - https://orcid.org/0000-0002-3319-3940 Bartłomiej J. Jankiewicz - https://orcid.org/0000-0002-1172-8764

\section{References}

1. Wang, X.; Feng, J.; Bai, Y.; Zhang, Q.; Yin, Y. Chem. Rev. 2016, 116, 10983-11060. doi:10.1021/acs.chemrev.5b00731
2. Liu, X.; locozzia, J.; Wang, Y.; Cui, X.; Chen, Y.; Zhao, S.; Li, Z.; Lin, Z. Energy Environ. Sci. 2017, 10, 402-434. doi:10.1039/c6ee02265k

3. Pérez-Lorenzo, M.; Vaz, B.; Salgueiriño, V.; Correa-Duarte, M. A. Chem. - Eur. J. 2013, 19, 12196-12211. doi:10.1002/chem.201301802

4. Lee, J.; Kim, S. M.; Lee, I. S. Nano Today 2014, 9, 631-667. doi:10.1016/j.nantod.2014.09.003

5. Zhang, C.; Zhou, Y.; Zhang, Y.; Zhao, S.; Fang, J.; Sheng, X. Appl. Organomet. Chem. 2018, 32, e4160. doi:10.1002/aoc.4160

6. Li, Y.-Y.; Wang, J.-G.; Liu, X.-R.; Shen, C.; Xie, K.; Wei, B. ACS Appl. Mater. Interfaces 2017, 9, 31691-31698. doi:10.1021/acsami.7b04624

7. Xiang, Q.; Yu, J.; Cheng, B.; Ong, H. C. Chem. - Asian J. 2010, 5, 1466-1474. doi:10.1002/asia.200900695

8. Zuo, J.; Keil, P.; Grundmeier, G. Appl. Surf. Sci. 2012, 258, 7231-7237. doi:10.1016/j.apsusc.2012.04.054

9. Linic, S.; Christopher, P.; Ingram, D. B. Nat. Mater. 2011, 10, 911-921. doi:10.1038/nmat3151

10. Yu, Y.; Cao, C. Y.; Chen, Z.; Liu, H.; Li, P.; Dou, Z. F.; Song, W. G. Chem. Commun. 2013, 49, 3116. doi:10.1039/c3cc39212k

11. Li, Q.; Zhang, C.; Ma, J.; Wang, G.; Ng, D. H. L. ChemCatChem 2014, 6, 1392-1400. doi:10.1002/cctc.201300994

12. Boxi, S. S.; Paria, S. RSC Adv. 2015, 5, 37657-37668. doi:10.1039/c5ra03421c

13. Kong, L.; Duan, G.; Zuo, G.; Cai, W.; Cheng, Z. Mater. Chem. Phys. 2010, 123, 421-426. doi:10.1016/j.matchemphys.2010.04.034

14. Zheng, H.; Svengren, H.; Huang, Z.; Yang, Z.; Zou, X.; Johnsson, M. Microporous Mesoporous Mater. 2018, 264, 147-150. doi:10.1016/j.micromeso.2018.01.012

15. Lu, J.; Su, F.; Huang, Z.; Zhang, C.; Liu, Y.; Ma, X.; Gong, J. RSC Adv. 2013, 3, 720-724. doi:10.1039/c2ra22713d

16. Wang, S.; Qian, H.; Hu, Y.; Dai, W.; Zhong, Y.; Chen, J.; Hu, X. Dalton Trans. 2013, 42, 1122-1128. doi:10.1039/c2dt32040a

17. Yin, H.; Wang, X.; Wang, L.; Nie, Q.; Zhang, Y.; Yuan, Q.; Wu, W. J. Alloys Compd. 2016, 657, 44-52. doi:10.1016/j.jallcom.2015.10.055

18. Yin, Z.; Quu, S.; Chen, W.; Li, H.; Cheng, L.; Cao, S. Mater. Lett. 2018, 214, 202-204. doi:10.1016/j.matlet.2017.11.123

19. Song, C.; Wang, D.; Gu, G.; Lin, Y.; Yang, J.; Chen, L.; Fu, X.; Hu, Z J. Colloid Interface Sci. 2004, 272, 340-344. doi:10.1016/j.jcis.2003.08.062

20. Bartosewicz, B.; Michalska-Domańska, M.; Liszewska, M.; Zasada, D.; Jankiewicz, B. J. Beilstein J. Nanotechnol. 2017, 8, 2083-2093. doi:10.3762/bjnano.8.208

21. Zilberberg, L.; Mitlin, S.; Shankar, H.; Asscher, M. J. Phys. Chem. C 2015, 119, 28979-28991. doi:10.1021/acs.jpcc.5b09621

22. Liu, Y.; Zhang, W.; Sun, Y.; Liang, W. Mater. Res. Bull. 2018, 98 , 240-249. doi:10.1016/j.materresbull.2017.10.027

23. Kulczyk-Malecka, J.; Kelly, P. J.; West, G.; Clarke, G. C. B.; Ridealgh, J. A.; Almtoft, K. P.; Greer, A. L.; Barber, Z. H. Acta Mater. 2014, 66, 396-404. doi:10.1016/j.actamat.2013.11.030

24. García-Serrano, J.; Gómez-Hernández, E.; Ocampo-Fernández, M.; Pal, U. Curr. Appl. Phys. 2009, 9, 1097-1105. doi:10.1016/j.cap.2008.12.008

25. Zhang, H.; Liang, C.; Liu, J.; Tian, Z.; Wang, G.; Cai, W. Langmuir 2012, 28, 3938-3944. doi:10.1021/la2043526

26. Graf, M.; Haensch, M.; Carstens, J.; Wittstock, G.; Weissmüller, J. Nanoscale 2017, 9, 17839-17848. doi:10.1039/c7nr05124g

27. X-ray Photoelectron Spectroscopy (XPS) Reference Pages - Atom. http://www.xpsfitting.com/search/label/Silver (accessed Jan 2, 2020).

28. Wang, C.; Yu, J.; Hu, M.-y.; Zhang, K.-h. J. Alloys Compd. 2018, 747, 966-971. doi:10.1016/j.jallcom.2018.03.098 
29. Ghosh, A.; Norton, B. Sol. Energy Mater. Sol. Cells 2017, 163,

178-184. doi:10.1016/j.solmat.2017.01.036

30. Clavero, C. Nat. Photonics 2014, 8, 95-103.

doi:10.1038/nphoton.2013.238

\section{License and Terms}

This is an Open Access article under the terms of the Creative Commons Attribution License

(https://creativecommons.org/licenses/by/4.0). Please note that the reuse, redistribution and reproduction in particular requires that the authors and source are credited.

The license is subject to the Beilstein Journal of

Nanotechnology terms and conditions:

(https://www.beilstein-journals.org/bjnano)

The definitive version of this article is the electronic one which can be found at:

doi:10.3762/bjnano.11.12 